CLINICAL STUDY

\title{
Quality of life is impaired in association with the need for prolonged postoperative therapy by somatostatin analogs in patients with acromegaly
}

\author{
Mark R Postma $^{1}$, Romana T Netea-Maier ${ }^{3}$, Gerrit van den Berg ${ }^{1}$, Jens Homan ${ }^{3}$, Wim J Sluiter ${ }^{1}$, \\ Margreet A Wagenmakers ${ }^{3}$, Alfons C M van den Bergh ${ }^{2}$, Bruce H R Wolffenbuttel ${ }^{1}$, Ad R M M Hermus ${ }^{3}$ \\ and André P van Beek ${ }^{1}$ \\ Departments of ${ }^{1}$ Endocrinology and ${ }^{2}$ Radiation Oncology, University Medical Center Groningen, University of Groningen, PO Box 30.001, 9700 RB \\ Groningen, The Netherlands and ${ }^{3}$ Department of Endocrinology, Radboud University Nijmegen Medical Center, Nijmegen, \\ The Netherlands \\ (Correspondence should be addressed to A P van Beek; Email: a.p.van.beek@int.umcg.nl)
}

\begin{abstract}
Objective: To assess the influence of long-acting somatostatin analogs (SSTA) after initial pituitary surgery on long-term health-related quality of life (HR-QoL) in relation to disease control in patients with acromegaly.

Design: This is a cross-sectional study in two tertiary referral centers in The Netherlands.

Patients and methods: One hundred and eight patients with acromegaly, in whom transsphenoidal $(n=101,94 \%)$ or transcranial $(n=7,6 \%)$ surgery was performed. Subsequently, $46(43 \%)$ received additional radiotherapy and $41(38 \%)$ were on postoperative treatment with SSTA because of persistent or recurrent disease at the time of study. All subjects filled in standardized questionnaires measuring HR-QoL. Disease control at the time of study was assessed by local IGF1 SDS.

Results: IGF1 SDS were slightly higher in patients treated with SSTA in comparison with patients without use of SSTA $(0.85 \pm 1.52$ vs $0.25 \pm 1.21, P=0.026)$, but the percentage of patients with insufficient control (IGF1 SDS >2) was not different (17 vs $9 \%, P=0.208$ ). Patients using SSTA reported poorer scores on most subscales of the RAND-36 and the acromegaly QoL and on all subscales of the multidimensional fatigue inventory-20. A subgroup analysis in patients with similar IGF1 levels (SSTA,$+ n=26$, IGF1 SDS $0.44 \pm 0.72$ vs SSTA,$- n=44$, IGF1 SDS $0.41 \pm 0.65$ ) revealed worse scores on physical functioning, physical fatigue, reduced activity, vitality, and general health perception across all HR-QoL questionnaires in patients treated with SSTA.

Conclusion: QoL is impaired in association with the need for prolonged postoperative therapy by SSTA in patients with acromegaly despite similar IGF1 levels.

European Journal of Endocrinology 166 585-592
\end{abstract}

\section{Introduction}

Treatment options for patients with acromegaly have greatly evolved during the past decades. Transsphenoidal surgery (TSS) is currently the treatment of choice for most GH-producing pituitary adenomas. However, cure is not achieved in 5-25\% of microadenomas and $32-60 \%$ of macroadenomas $(1,2)$, necessitating other treatment modalities for disease control such as radiotherapy (RT) and medical treatment.

RT is effective in lowering serum GH and IGF1 concentrations in patients with acromegaly, with biochemical control of the disease being achieved in $60 \%$ of patients within 10 years after irradiation (3).

In addition, receptor targets for medical therapy have emerged. The most widely used group of medication is somatostatin analogs (SSTA), which were introduced in the 1980s. They bind to somatostatin receptors, thereby suppressing the secretion of $\mathrm{GH}$ and reducing somatotroph cell mass. They also act on the liver to block the synthesis of IGF1 (4). In about $60 \%$ of patients treated with SSTA, biochemical control can be achieved $(5,6)$. Other medical treatment options include $\mathrm{GH}$ receptor antagonists and dopamine agonists. Combinations of medical therapies are increasingly applied (7).

Quality of life (QoL) is reported to be severely impaired in patients with acromegaly, measured both by general health-related and by disease-specific questionnaires $(8,9)$. Patients with biochemically controlled acromegaly have significantly better QoL than patients with persistent disease $(10,11,12,13)$. Other factors associated with reduced QoL in patients with acromegaly are prior RT, presence of clinical osteoarthritis, and GH deficiency $(14,15,16)$. 
Less is known about QoL in patients treated with SSTA, despite the fact that a substantial portion of patients with acromegaly use this medication for biochemical control of their disease (17). Only two studies investigated the effects of SSTA on QoL and concluded that improvement of symptoms relating to psychological distress, well-being, social fears, and QoL occurs after treatment with Lanreotide $(18,19)$. However, these studies did not compare the effects on QoL with other treatment modalities. In fact, Hua et al. (20) are the only ones reporting effects of treatment with or without SSTA on QoL related to remission status in acromegaly. In their small study, use of SSTA was associated with worse acromegaly QoL (AcroQoL) scores in patients with disease control. Although patients with SSTA had higher IGF1 concentrations than patients without SSTA, this did not reach significance. Furthermore, they found no effect of remission status on QoL. Thus, controversy exists because these findings are in contrast to previous studies showing that both controlled disease and IGF1 are associated with improved QoL $(10,11,12)$.

Therefore, we investigated the influence of postoperative use of long-acting SSTA on long-term health-related QoL (HR-QoL) in relation to disease control in patients surgically treated for acromegaly in a large cross-sectional study in two tertiary referral centers.

\section{Patients and methods}

\section{Study population}

Patients with acromegaly were recruited for participation at the endocrine outpatient clinics of the University Medical Center Groningen (UMCG) and the Radboud University Nijmegen Medical Center, which are both large tertiary referral centers for pituitary surgery. All patients were between 20 and 75 years old. These age criteria were chosen because appropriate local reference data with regard to QoL are available. The initial diagnosis of acromegaly was based on the characteristic clinical signs and symptoms and confirmed by insufficient suppression of GH during an oral glucose tolerance test (oGTT), elevated ageadjusted IGF1 concentrations, and the presence of a pituitary adenoma on radiologic imaging. Patients were only recruited for participation if they were still actively followed at our endocrine outpatient clinics to ensure accuracy and completeness of data collection. All patients included in this study underwent surgery as primary treatment, in some cases followed by a second surgical procedure. Surgery was performed in both centers by specialized pituitary neurosurgeons between 1975 and 2008. RT was given postoperatively as previously described (21). SSTA were prescribed postoperatively in case of persistent or recurrent disease in accordance with the standard of care at the time of treatment (1). In The Netherlands, short-acting SSTA have been available from 1985 and long-acting SSTA from 1989.

Questionnaires on QoL, use of medication, presence of comorbidity, and social status were sent to all patients by mail. Questionnaires were returned by mail.

Use of medication and presence of comorbidity were also confirmed by investigation of the medical charts. The interval between last treatment (surgery, RT, or initiation of SSTA) and QoL assessment was at least 12 months.

Baseline demographic characteristics (age, gender, and life expectancy), tumor size, type and outcome of treatment (recurrent or persistent disease, hormonal substitution therapy), and biochemical control of acromegaly at the time of the study were collected. In addition, data with regard to the use of SSTA, GH receptor antagonists, and dopamine agonists at last visit were recorded.

Disease activity was assessed by regular oGTT (except in patients treated with SSTA or Pegvisomant) and measurement of serum GH and IGF1 concentrations. For the present analysis, disease control at the time of study was assessed by IGF1. Pituitary insufficiency was treated with $\mathrm{L}-\mathrm{T}_{4}$, glucocorticoid supplementation, testosterone, or estrogens (in premenopausal women) when deficiencies were documented using appropriate basal hormone and dynamic tests (22).

Patients of the UMCG participated in 2005 and patients of Radboud University Nijmegen Medical Center in 2008 and 2009.

Approval was given by the medical ethics review committee of both centers.

\section{Definitions}

Criteria for remission and relapse Remission was defined as the disappearance of clinical signs of active GH hypersecretion in addition to normal IGF1 concentrations $(\leq$ mean +2 s.D.s for age) and suppression of serum GH levels during OGTT $<1.0 \mu \mathrm{g} / \mathrm{l}$ within the first 3 months after surgery.

Relapse was defined as the development of clinical signs of active GH hypersecretion after initial remission with elevated IGF1 concentrations $(>$ mean +2 s.D.s for age) and serum GH levels $\geq 1.0 \mu \mathrm{g} / \mathrm{l}$ during OGTT.

Biochemical disease control was defined as normal IGF1 concentrations ( $\leq$ mean +2 s.D.s for age).

\section{Laboratory assays}

In Groningen, plasma IGF1 was measured by RIA after acid-ethanol extraction (Nichols Institute of Diagnostics, San-Juan Capistrano, CA, USA) (21). In Nijmegen, serum IGF1 was measured by an in-house RIA (23). 
For each IGF1 assay reference values were derived from healthy subjects. For the purpose of uniform reporting, IGF1 results are primarily expressed as agecorrected SDS, allowing direct comparison between both centers.

For the analysis of IGF1 SDS, only those scores were analyzed that were measured within the last year of follow-up and at least 3 months after surgery, after initiation or withdrawal of SSTA, to properly reflect disease activity after a change in therapy. This is consistent with clinical guidelines regarding reliability of IGF1 measurements (24).

\section{QoL questionnaires}

RAND-36 HR-QoL was measured with the RAND-36, which is identical to the 36-item short-form health survey (SF-36). Both versions are nowadays available in the public domain. The SF-36 and RAND-36 include the same set of items. Only scoring of the general health and pain subscales is different, but the differences are very small between both scoring systems. The questionnaire contains 36 questions recording various dimensions of general well-being over the previous 4 weeks. The items are formulated as statements or questions with Likert scale response options. The 36 questions are organized into nine scales (physical functioning, physical problems, bodily pain, general health, vitality, social functioning, emotional problems, and mental health) that are linearly converted to a scale of 0-100. The first three parameters measure physical health, the last three parameters measure mental health and the general health and vitality scales are sensitive to both physical and mental health outcomes. Higher scores represent better QoL (25). Normative data by age are available for the Dutch population (26).

Multidimensional fatigue inventory-20 The multidimensional fatigue inventory-20 (MFI-20) records fatigue and contains 20 statements, organized into five scales (general fatigue, physical fatigue, reduced activity, reduced motivation, and mental fatigue), with a maximum score of 20 on each subscale (27). Higher scores indicate a higher level of fatigue or impairment. Dutch normative data were derived from Smets et al. (28).

Hospital Anxiety and Depression Scale The Hospital Anxiety and Depression Scale (HADS) consists of 14 items related to anxiety and depression (29). Each item is scored as a number, with a maximal score for each subscale (anxiety or depression) of 21, higher scores indicating more severe anxiety or depression. Clinical depression or anxiety is indicated by a score of 6 or higher on the depression scale or 7 or higher on the anxiety scale. Dutch normative data were derived from Spinhoven et al. (30).
Acromegaly QoL The AcroQoL Questionnaire is a disease-specific questionnaire, which is suitable for measuring HR-QoL. It comprises 22 questions. Each question has five possible answers scored from 1 to 5 , with a total maximum score of 110 , which is quoted as a percentage. A score of 110 reflects the best possible QoL. The 22 questions are divided into the two main categories of physical and psychological function. The psychological dimension is subdivided into the subdimensions of appearance and personal relationships $(31,32)$.

\section{Statistical analysis}

Differences were assessed with $t$-tests (for continuous variables) or $\chi^{2}$ tests (for categorical variables). An alpha level of 0.05 was used for determining the statistical significance. For graphical representation, study population mean SDS with 95\% confidence intervals are shown. SPSS 18.0.3 (SPSS, Inc., Armonk, NY, USA) was used for data analysis.

\section{Results}

\section{Study population}

One hundred and sixty-four patients were eligible for the present study and were sent questionnaires on HR and acromegaly-specific QoL, mood, and fatigue by mail. One hundred and eight patients (of which 47 men and 61 women, age $44 \pm 12$ years) returned all questionnaires (response rate of $66 \%$ ). TSS was performed in 101 $(94 \%)$, and a transcranial approach was used in seven

Table 1 Demographic characteristics and outcome of treatment data of patients with or without use of SSTA. Data are given as absolute number (\%) or as mean \pm s.D.

\begin{tabular}{lccc}
\hline & SSTA + & SSTA & P value \\
\hline Number & 41 & 67 & \\
Age at diagnosis (years) & $40.6 \pm 11.3$ & $42.2 \pm 10.6$ & NS \\
Gender (male/female) & $24 / 17$ & $23 / 44$ & 0.014 \\
Age at study & $54.8 \pm 11.6$ & $53.6 \pm 11.2$ & NS \\
Macroadenoma & $30(73)$ & $52(78)$ & NS \\
TSS/craniotomy & $38 / 3$ & $63 / 4$ & NS \\
Second surgical procedure & $8(20)$ & $5(7)$ & NS \\
Cured after surgery & $0(0)$ & $38(57)$ & \\
Radiotherapy & $17(41)$ & $29(43)$ & NS \\
Medication at last visit & & & \\
Somatostatin analog & $41(100)$ & $0(0)$ & NS \\
Pegvisomant & $4(10)$ & $4(6)$ & 0.010 \\
Dopamine agonist & $7(17)$ & $2(3)$ & NS \\
Substitution of pituitary axis & & & NS \\
Thyroid hormone & $20(49)$ & $22(33)$ & \\
Glucocorticoids & $17(41)$ & $21(31)$ & NS \\
Sex hormones & & & NS \\
Men & $14(58)$ & $8(35)$ & NS \\
Women & $2(12)$ & $4(9)$ & $3(4)$ \\
GH & $0(0)$ & $3(4)$ & \\
Antidiuretic hormone & $3(7)$ & & \\
\hline
\end{tabular}

TSS, transsphenoidal surgery; NS, not significant. 
Table 2 Daily activities, comorbidity, and mood in patients with or without use of SSTA. Data are given as absolute number (\%) or as mean \pm S.D.

\begin{tabular}{|c|c|c|c|}
\hline & SSTA+ & SSTA- & $P$ value \\
\hline $\begin{array}{l}\text { Number } \\
\text { HADS }\end{array}$ & 41 & 67 & \\
\hline Anxiety & $5.1 \pm 3.6$ & $4.9 \pm 4.1$ & NS \\
\hline Depression & $5.1 \pm 3.7$ & $4.3 \pm 4.1$ & NS \\
\hline \multicolumn{4}{|l|}{ Daily activities } \\
\hline Paid work & $20(49)$ & $31(46)$ & NS \\
\hline Full-time employment & $16(39)$ & $28(42)$ & NS \\
\hline Working hours/week & $34 \pm 11$ & $30 \pm 12$ & $\begin{array}{l}\text { NS } \\
\text { NS }\end{array}$ \\
\hline Comorbidity & & & NS \\
\hline Heart disease & $5(12)$ & $2(3)$ & NS \\
\hline Hypertension & $15(37)$ & $23(34)$ & NS \\
\hline $\begin{array}{l}\text { Cerebrovascular } \\
\text { disease }\end{array}$ & $0(0)$ & $1(1)$ & NS \\
\hline Type 2 diabetes & $6(15)$ & $4(6)$ & NS \\
\hline Malignancy & $2(5)$ & $1(1)$ & NS \\
\hline Psychological problems & $3(7)$ & $11(16)$ & NS \\
\hline Arthritis/arthrosis & $10(24)$ & 22 (33) & NS \\
\hline
\end{tabular}

NS, not significant.

(6\%) patients. A second surgical procedure was performed in $13(12 \%)$ of patients because of persistent or recurrent disease. Forty-six patients $(43 \%)$ received postoperative RT. Treatment with SSTA was used by 41 patients $(38 \%)$ at the time of study. The baseline characteristics including IGF1 SDS of the entire cohort of acromegalic patients who received primary surgical treatment in our centers did not differ from the present study population.

\section{Patient groups}

The characteristics of patients who were using SSTA at the last visit (SSTA + ) compared to those who were not $($ SSTA -$)$ are shown in Table 1 . The patients in the SSTA + group had a macroadenoma, a craniotomy, a second surgical procedure, and postoperative RT as often as patients in the SSTA - group. There was a trend toward more thyroid hormone substitution in the SSTA + group, but there were no differences in frequency of substitution of other pituitary insufficiencies. Feelings of anxiety and depression (HADS) were comparable between groups and not indicative of a state of clinical anxiety or depression (Table 2). Social status, full-time/part-time employment, social security benefit, and comorbidities were all similar between groups at the time of assessment (Table 2).

\section{IGF1 SDS and HR-QoL}

IGF1 SDS were higher in the patients treated with SSTA compared with the patients without use of SSTA $(0.85 \pm 1.52$ vs $0.25 \pm 1.21, P=0.026)$, but the percentage of patients with insufficient (biochemical) control (IGF1 SDS > 2) was not different between the two groups (17 vs 9\%, $P=0.208$ ). Patients using SSTA reported poorer scores on five of the eight subscales of the RAND-36 and on all subscales of the MFI-20 (Table 3). In addition, scores on the AcroQoL were worse in patients treated with SSTA. Figure 1 shows the differences in SDS between the two groups with respect to the IGF1, HADS, RAND-36, and MFI-20.

\section{HR-QoL, subgroup analysis corrected for IGF1 SDS}

For a subgroup analysis all patients with an IGF1 SDS between +1.5 and -1 were selected. This resulted in a group of 26 patients using SSTA at the time of this study and 44 patients who were not treated with SSTA. Both groups had similar biochemical control as measured by IGF1 SDS (SSTA + 0.44 \pm 0.72 vs SSTA $-0.41 \pm 0.65$ ). Patients treated with SSTA reported significantly worse scores on physical functioning, physical fatigue, reduced activity, vitality, and general health perception across all HR-QoL questionnaires (Fig. 2).

In multivariate analysis, SSTA use and female gender were highly significantly associated with worse scores on the AcroQoL, but age, RT, and IGF1 SDS were not (Table 4).

Table 3 QoL in patients with or without use of SSTA.

\begin{tabular}{|c|c|c|c|c|}
\hline & \multicolumn{2}{|c|}{ Mean \pm s.D. } & \multirow[b]{2}{*}{$P$ value ${ }^{*}$} & \multirow{2}{*}{$\begin{array}{l}\text { Population } \\
\text { reference }\end{array}$} \\
\hline & SSTA + & SSTA - & & \\
\hline \multicolumn{5}{|l|}{ RAND-36 } \\
\hline Physical functioning & $65 \pm 26$ & $79 \pm 23$ & 0.004 & $82 \pm 23$ \\
\hline Social functioning & $66 \pm 27$ & $75 \pm 25$ & NS & $87 \pm 21$ \\
\hline $\begin{array}{l}\text { Role limitations } \\
\text { physical problems }\end{array}$ & $46 \pm 40$ & $65 \pm 44$ & 0.024 & $79 \pm 36$ \\
\hline $\begin{array}{l}\text { Role limitations } \\
\text { emotional problems }\end{array}$ & $78 \pm 36$ & $75 \pm 39$ & NS & $84 \pm 32$ \\
\hline Mental health & $72 \pm 16$ & $75 \pm 17$ & NS & $77 \pm 18$ \\
\hline Vitality & $48 \pm 24$ & $58 \pm 20$ & 0.015 & $67 \pm 20$ \\
\hline Pain & $65 \pm 27$ & $78 \pm 23$ & 0.010 & $80 \pm 26$ \\
\hline $\begin{array}{l}\text { General health } \\
\text { perception }\end{array}$ & $49 \pm 22$ & $63 \pm 23$ & 0.003 & $73 \pm 23$ \\
\hline \multicolumn{5}{|l|}{ MFI-20 } \\
\hline General fatigue & $14.2 \pm 4.7$ & $12.1 \pm 5.5$ & 0.050 & $9.9 \pm 5.2$ \\
\hline Physical fatigue & $14.0 \pm 4.5$ & $10.4 \pm 5.1$ & $<0.001$ & $8.8 \pm 4.9$ \\
\hline Mental fatigue & $11.6 \pm 4.9$ & $9.5 \pm 5.0$ & 0.042 & $8.7 \pm 4.6$ \\
\hline Reduced activity & $12.0 \pm 5.2$ & $9.5 \pm 4.1$ & 0.008 & $8.2 \pm 4.0$ \\
\hline Reduced motivation & $11.0 \pm 4.8$ & $9.0 \pm 4.3$ & 0.031 & $8.3 \pm 4.8$ \\
\hline \multicolumn{5}{|l|}{ AcroQoL } \\
\hline Physical & $25.2 \pm 6.8$ & $28.7 \pm 7.1$ & 0.012 & NA \\
\hline Psychological & $46.5 \pm 10.8$ & $50.7 \pm 9.9$ & 0.046 & NA \\
\hline $\begin{array}{l}\text { Subscale } \\
\text { appearance }\end{array}$ & $21.1 \pm 6.1$ & $23.8 \pm 5.5$ & 0.019 & NA \\
\hline $\begin{array}{l}\text { Subscale personal } \\
\text { relations }\end{array}$ & $25.7 \pm 5.3$ & $26.9 \pm 5.4$ & NS & NA \\
\hline Total score & $71.7 \pm 16.8$ & $79.2 \pm 15.5$ & 0.022 & NA \\
\hline
\end{tabular}

SSTA + , use of SSTA at the time of study; SSTA - , no use of SSTA at the time of study; NA, not applicable; NS, not significant. ${ }^{*} P$ value SSTA + vs SST - . 


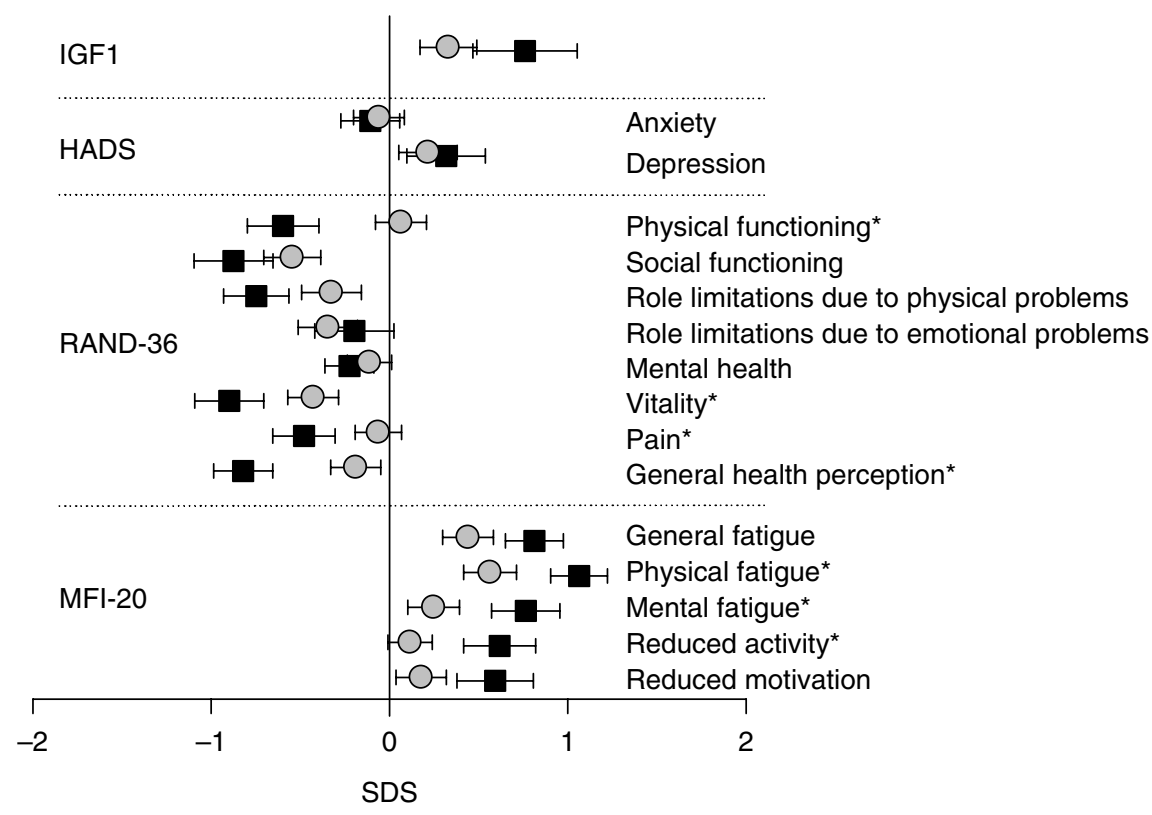

Figure 1 SDS for IGF1, HADS, RAND-36, and MFI-20 in patients treated with or without SSTA. Grey circles are patients without somatostatin analogs at time of the study. Black squares are patients with somatostatin analogs at time of the study. Data represent mean $\pm 95 \%$ confidence interval of mean. ${ }^{*} P<0.05$ for mean differences.

\section{Discussion}

In this study we observed that QoL was impaired in association with the need for prolonged postoperative therapy with SSTA in patients with acromegaly despite similar IGF1 levels. This association was found across all HR-QoL questionnaires. The differences that were found can be considered clinically relevant, since differences of more than ten points were found in the RAND-36 subscales (26). Subjects treated with SSTA had lower scores with regard to physical functioning, physical fatigue, reduced activity, vitality, and general health perception. These differences could not be attributed to differences in mood, patient characteristics, or comorbidities.

This is the first QoL study that takes both biochemical control by IGF1 SDS and the use of SSTA into account. Both groups of patients, with or without SSTA, were highly similar with regard to age, hormonal substitution, and comorbidities. Further, our study did not rely only on the disease-specific AcroQoL but also on generic scales measuring HR-QoL and fatigue. A previous study by Hua et al. (20) showed that in the group of patients with disease control, treatment with

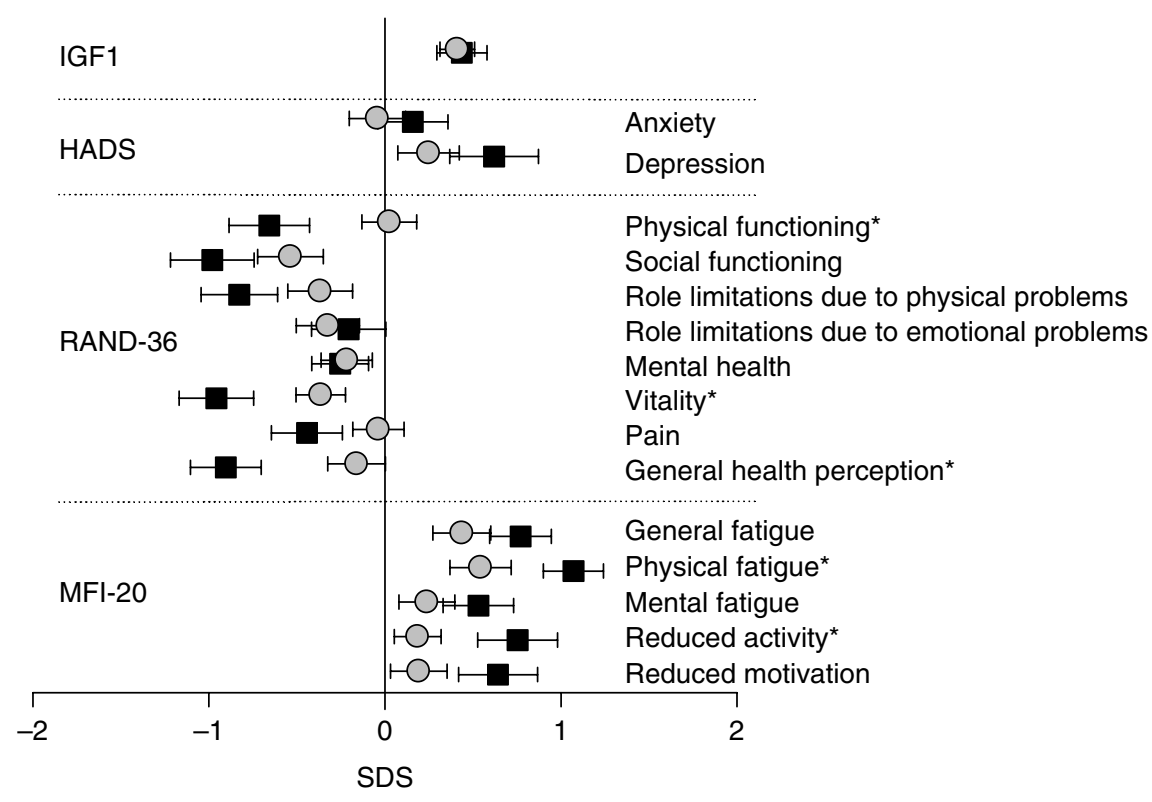

Figure 2 SDS for IGF1, HADS, RAND36 , and MFI-20 in patients treated with or without SSTA matched for IGF1 SDS. Grey circles are patients without somatostatin analogs at time of the study. Black squares are patients with somatostatin analogs at time of the study. Data represent mean $\pm 95 \%$ confidence interval of mean. ${ }^{*} P<0.05$ for mean differences. 
Table 4 Multivariate analysis of age, gender, treatment (SSTA and radiotherapy) and IGF1 SDS on AcroQoL subscales and total score.

\begin{tabular}{|c|c|c|c|c|c|c|c|c|c|c|}
\hline \multirow[b]{3}{*}{ Variable } & \multicolumn{8}{|c|}{ AcroQoL subscale } & & \\
\hline & \multicolumn{2}{|c|}{ Physical } & \multicolumn{2}{|c|}{ Psychological } & \multicolumn{2}{|c|}{ Appearance } & \multicolumn{2}{|c|}{ Relations } & \multicolumn{2}{|c|}{ Total score } \\
\hline & $\beta$ & $P$ value & $\beta$ & $P$ value & $\beta$ & $P$ value & $\beta$ & $P$ value & $\beta$ & $P$ value \\
\hline Age (years) & -0.159 & 0.097 & -0.132 & 0.175 & -0.147 & 0.122 & -0.101 & 0.312 & -0.160 & 0.097 \\
\hline Gender (male vs female) & -0.177 & 0.071 & -0.271 & 0.008 & -0.275 & 0.005 & -0.193 & 0.063 & -0.259 & 0.010 \\
\hline SSTA $(-v S+)$ & -0.274 & 0.005 & -0.265 & 0.008 & -0.289 & 0.003 & -0.167 & 0.102 & -0.286 & 0.004 \\
\hline Radiotherapy ( - vs + ) & -0.178 & 0.064 & -0.095 & 0.331 & -0.059 & 0.538 & -0.114 & 0.259 & -0.144 & 0.135 \\
\hline IGF1 SDS & -0.018 & 0.860 & 0.027 & 0.790 & 0.019 & 0.846 & 0.045 & 0.669 & 0.013 & 0.894 \\
\hline
\end{tabular}

SSTA, use of somatostatin analogs at the time of study; $\beta$, standardized regression coefficient.

Lanreotide was associated with worse AcroQoL scores. This study was small, comparing 13 patients on Lanreotide treatment with 17 patients with cure of disease. Our much larger study in two tertiary referral centers confirms and extends this finding by showing an association of poorer QoL and use of SSTA independent of IGF1 SDS.

For the subgroup analysis of patients with a similar IGF1 SDS, all patients with an IGF1 SDS $<-1$ and $>+1.5$ were excluded. These cutoff scores were chosen to maintain a sufficiently large group size and to exclude patients with subtle GH deficiency or excess. Previously, Kauppinen-Makelin et al. (11) described a U-shaped relationship of nadir GH levels in an oGTT with QoL. And GH deficiency is reported to be associated with decreased QoL in patients with prior acromegaly (16). As illustrated in Fig. 2, even in patients with identical IGF1 SDS the association of use of SSTA with poorer QoL persisted. In agreement, multivariate analysis explicitly performed to detect the influence of IGF1 SDS on the AcroQoL revealed similar results (Table 4).

In contrast to some studies we did not find an effect of IGF1 SDS or disease control on QoL $(10,11,12,13)$. One possibility is that only 13 of our total cohort of 108 patients were not biochemically controlled resulting in a group that is too small to detect differences. However, our findings are in agreement with other large studies that also failed to find a (long-term) effect of IGF1 on QoL $(11,33)$, suggesting perhaps that factors other than serum IGF1 participate in the well-being of acromegalic patients. It can be speculated that this may be glycemic control. However, the presence of type $2 \mathrm{DM}$ was not found to be a significant contributor to the AcroQoL scores (data not shown).

Our study is limited by its cross-sectional design to infer causality between the use of SSTA and QoL. It suggests by association that different treatment modalities in acromegaly result in different disease-related outcomes. Another potential limitation is the use of IGF1 as a single measure of biochemical control. Although we agree that including $\mathrm{GH}$ concentrations in the present analysis would potentially be informative, it must be noted that use of medication to control GH concentrations interferes with GH secretory patterns (34) resulting in unreliable group comparisons with regard to random GH concentrations. In addition, clinical guidelines advocate not assessing disease activity by an oGTT while receiving medical treatment (1).

Previous studies have shown that levels of GH and IGF 1 may be discordant in several circumstances (35, 36). This potentially suggests that impaired QoL may be a result of different $\mathrm{GH}$ concentrations and secretory profiles in spite of normalized IGF1 SDS. Indeed, Biermasz et al. (34) demonstrated that octreotide represses secretory-burst mass and nonpulsatile secretion but does not lead to restoration of event frequency or orderly GH secretion in acromegaly. In addition, a new concept of extrahepatic acromegaly induced by SSTA has been introduced. It is postulated by Neggers et al. (37) that long-acting SSTA normalize serum IGF1 levels in certain patients in the presence of elevated GH actions in extrahepatic tissues. Also, Rubeck et al. (38) compared traditional and novel biomarkers and health status in patients with acromegaly treated with either surgery alone or SSTA. These authors concluded that despite similar and normalized IGF1 levels, SSTA treatment compared with surgery alone was associated with less suppressed GH levels and less symptom relief. These discordant findings were speculated to be attributed to the specific suppression of hepatic IGF1 production by SSTA. It led to their recommendation that biochemical assessment during SSTA treatment should include both GH and IGF1. All these studies point to biological effects of subtle abnormalities in GH secretion in patients treated with SSTA. A practical consequence of this may be that relying solely on normalization of IGF1 SDS may be falsely reassuring.

Besides the possibility of differences in GH concentrations in controlled and cured patients, the alternative of a direct negative influence of SSTA on QoL by a GH-independent mechanism must be considered. SSTA is a nonspecific inhibitor of various hormone systems and has also been associated with persistent diastolic dysfunction (39), increased sleep latency (40), and fatsoluble vitamin deficiency (41).

Patients without use of SSTA were more often women. This may have underestimated differences, since it is well known that women report a lower QoL than men (26). In addition, differences in hormone 
substitution may be of relevance. However, we have previously shown that this was not an important confounder in patients with nonfunctioning pituitary macroadenomas (21). Multivariate analysis (data not shown) also did not point in this direction. Other treatment modalities like RT have been reported to negatively influence QoL in acromegaly $(11,14)$. In our study, both univariate and multivariate analyses did not show a significant effect of RT on many subscales of QoL. It must be noted that patients who underwent pituitary RT had better biochemical control than those who did not receive RT (IGF1 SDS $0.12 \pm 0.17$ vs $0.75 \pm 0.18$, $P<0.001)$. However, a trend toward worse QoL in one (physical) subscale of the AcroQoL was seen in patients who underwent RT.

Our study points out that achievement of all treatment goals is not obvious for every therapeutic modality. Different treatment options may result in similar biochemical control, but their efficacy on several other treatment goals, such as QoL, may vary. Differences may be explained by subtle but persistent underlying disease activity or an intrinsic negative effect of treatment.

In conclusion, patients treated with SSTA for acromegaly report a substantially poorer QoL. These findings were independent of IGF1 SDS.

\section{Declaration of interest}

The authors declare that there is no conflict of interest that could be perceived as prejudicing the impartiality of the research reported.

\section{Funding}

This research did not receive any specific grant from any funding agency in the public, commercial or not-for-profit sector.

\section{References}

1 Melmed S, Colao A, Barkan A, Molitch M, Grossman AB, Kleinberg D, Clemmons D, Chanson P, Laws E, Schlechte J, Vance ML, Ho K, Giustina A \& Acromegaly Consensus Group. Guidelines for acromegaly management: an update. Journal of Clinical Endocrinology and Metabolism 200994 1509-1517. (doi:10.1210/jc.2008-2421)

2 Wagenmakers MA, Netea-Maier RT, van Lindert EJ, Pieters GF, Grotenhuis AJ \& Hermus AR. Results of endoscopic transsphenoidal pituitary surgery in 40 patients with a growth hormonesecreting macroadenoma. Acta Neurochirurgica $2011 \mathbf{1 5 3}$ 1391-1399. (doi:10.1007/s00701-011-0959-8)

3 Jenkins PJ, Bates P, Carson MN, Stewart PM \& Wass JA. Conventional pituitary irradiation is effective in lowering serum growth hormone and insulin-like growth factor-I in patients with acromegaly. Journal of Clinical Endocrinology and Metabolism 2006 91 1239-1245. (doi:10.1210/jc.2005-1616)

4 Murray RD, Kim K, Ren SG, Chelly M, Umehara Y \& Melmed S. Central and peripheral actions of somatostatin on the growth hormone-IGF-I axis. Journal of Clinical Investigation $2004 \mathbf{1 1 4}$ 349-356. (doi:10.1172/JCI200419933)

5 Cozzi R, Montini M, Attanasio R, Albizzi M, Lasio G, Lodrini S, Doneda P, Cortesi L \& Pagani G. Primary treatment of acromegaly with octreotide LAR: a long-term (up to nine years) prospective study of its efficacy in the control of disease activity and tumor shrinkage. Journal of Clinical Endocrinology and Metabolism 2006 91 1397-1403. (doi:10.1210/jc.2005-2347)

6 Ronchi CL, Varca V, Beck-Peccoz P, Orsi E, Donadio F, Baccarelli A, Giavoli C, Ferrante E, Lania A, Spada A \& Arosio M. Comparison between six-year therapy with long-acting somatostatin analogs and successful surgery in acromegaly: effects on cardiovascular risk factors. Journal of Clinical Endocrinology and Metabolism 2006 91 121-128. (doi:10.1210/jc.2005-1704)

7 Melmed S. Medical progress: acromegaly. New England Journal of Medicine 2006355 2558-2573. (doi:10.1056/NEJMra062453)

8 Biermasz NR, van Thiel SW, Pereira AM, Hoftijzer HC, van Hemert AM, Smit JW, Romijn JA \& Roelfsema F. Decreased quality of life in patients with acromegaly despite long-term cure of growth hormone excess. Journal of Clinical Endocrinology and Metabolism 200489 5369-5376. (doi:10.1210/jc.2004-0669)

9 Rowles SV, Prieto L, Badia X, Shalet SM, Webb SM \& Trainer PJ. Quality of life (QOL) in patients with acromegaly is severely impaired: use of a novel measure of QOL: acromegaly quality of life questionnaire. Journal of Clinical Endocrinology and Metabolism 200590 3337-3341. (doi:10.1210/jc.2004-1565)

10 Trepp R, Everts R, Stettler C, Fischli S, Allemann S, Webb SM \& Christ ER. Assessment of quality of life in patients with uncontrolled vs. controlled acromegaly using the acromegaly quality of life questionnaire (AcroQoL). Clinical Endocrinology 200563 103-110. (doi:10.1111/j.1365-2265.2005.02307.x)

11 Kauppinen-Makelin R, Sane T, Sintonen H, Markkanen H, Valimaki MJ, Loyttyniemi E, Niskanen L, Reunanen A \& Stenman UH. Quality of life in treated patients with acromegaly. Journal of Clinical Endocrinology and Metabolism 200691 3891-3896. (doi:10.1210/jc.2006-0676)

12 Paisley AN, Rowles SV, Roberts ME, Webb SM, Badia X, Prieto L, Shalet SM \& Trainer PJ. Treatment of acromegaly improves quality of life, measured by AcroQol. Clinical Endocrinology $2007 \mathbf{6 7}$ 358-362. (doi:10.1111/j.1365-2265.2007.02891.x)

13 Matta MP, Couture E, Cazals L, Vezzosi D, Bennet A \& Caron P. Impaired quality of life of patients with acromegaly: control of GH/IGF-I excess improves psychological subscale appearance. European Journal of Endocrinology $2008 \quad \mathbf{1 5 8} \quad 305-310$. (doi:10.1530/EJE-07-0697)

14 van der Klaauw AA, Biermasz NR, Hoftijzer HC, Pereira AM \& Romijn JA. Previous radiotherapy negatively influences quality of life during 4 years of follow-up in patients cured from acromegaly. Clinical Endocrinology 200869 123-128. (doi:10.1111/j.13652265.2007.03169.x)

15 Wassenaar MJ, Biermasz NR, Kloppenburg M, Klaauw AA, Tiemensma J. Smit JW, Pereira AM, Roelfsema F, Kroon HM \& Romijn JA. Clinical osteoarthritis predicts physical and psychological QoL in acromegaly patients. Growth Hormone \& IGF Research 201020 226-233. (doi:10.1016/j.ghir.2010.02.003)

16 Wexler T, Gunnell L, Omer Z, Kuhlthau K, Beauregard C, Graham G, Utz AL, Biller B, Nachtigall L, Loeffler J, Swearingen B, Klibanski A \& Miller KK. Growth hormone deficiency is associated with decreased quality of life in patients with prior acromegaly. Journal of Clinical Endocrinology and Metabolism 200994 2471-2477. (doi:10.1210/jc.2008-2671)

17 Woodhouse LJ, Mukherjee A, Shalet SM \& Ezzat S. The influence of growth hormone status on physical impairments, functional limitations, and health-related quality of life in adults. Endocrine Reviews 200627 287-317. (doi:10.1210/er.2004-0022)

18 Lombardi G, Minuto F, Tamburrano G, Ambrosio MR, Arnaldi G, Arosio M, Chiarini V, Cozzi R, Grottoli S, Mantero F, Bogazzi F, Terzolo M, Tita P, Boscani PF \& Colao A. Efficacy of the new long-acting formulation of lanreotide (lanreotide Autogel) in somatostatin analogue-naive patients with acromegaly. Journal of Endocrinological Investigation 200932 202-209.

19 Sonino N, Scarpa E, Paoletta A, Fallo F \& Boscaro M. Slow-release lanreotide treatment in acromegaly: effects on quality of life. Psychotherapy and Psychosomatics 199968 165-167. (doi:10. 1159/000012326) 
20 Hua SC, Yan YH \& Chang TC. Associations of remission status and lanreotide treatment with quality of life in patients with treated acromegaly. European Journal of Endocrinology $2006 \mathbf{1 5 5}$ 831-837. (doi:10.1530/eje.1.02292)

21 van Beek AP, van den Bergh AC, van den Berg LM, van den Berg G, Keers JC, Langendijk JA \& Wolffenbuttel BH. Radiotherapy is not associated with reduced quality of life and cognitive function in patients treated for nonfunctioning pituitary adenoma. International Journal of Radiation Oncology, Biology, Physics 200768 986-991. (doi:10.1016/j.ijrobp.2007.01.017)

22 Brummelman P, Elderson MF, Dullaart RP, van den Bergh AC, Timmer CA, van den Berg G, Koerts J, Tucha O, Wolffenbuttel BH \& van Beek AP. Cognitive functioning in patients treated for nonfunctioning pituitary macroadenoma and the effects of pituitary radiotherapy. Clinical Endocrinology $2011 \mathbf{7 4} 481-487$. (doi:10.1111/j.1365-2265.2010.03947.x)

23 Span JP, Pieters GF, Sweep CG, Hermus AR \& Smals AG. Gender difference in insulin-like growth factor I response to growth hormone $(\mathrm{GH})$ treatment in GH-deficient adults: role of sex hormone replacement. Journal of Clinical Endocrinology and Metabolism 2000 85 1121-1125. (doi:10.1210/jc.85.3.1121)

24 Neggers SJ, van Aken MO, de Herder WW, Feelders RA, Janssen JA, Badia X, Webb SM \& van der Lely AJ. Quality of life in acromegalic patients during long-term somatostatin analog treatment with and without pegvisomant. Journal of Clinical Endocrinology and Metabolism 2008 93 3853-3859. (doi:10.1210/jc.2008-0669)

25 Brazier JE, Harper R, Jones NM, O'Cathain A, Thomas KJ, Usherwood T \& Westlake L. Validating the SF-36 health survey questionnaire: new outcome measure for primary care. BMJ 1992 305 160-164. (doi:10.1136/bmj.305.6846.160)

26 van der Zee KI \& Sanderman R. The Measurement of the General Health with the RAND-36, A Handbook, 1992 Rijks Universiteit Groningen, Noordelijk Centrum voor Gezondsheidsvraagstukken, Groningen, The Netherlands.

27 Smets EM, Garssen B, Bonke B \& De Haes JC. The multidimensional fatigue inventory (MFI) psychometric qualities of an instrument to assess fatigue. Journal of Psychosomatic Research 199539 315-325. (doi:10.1016/0022-3999(94)00125-O)

28 Smets EM, Visser MR, Willems-Groot AF, Garssen B, SchusterUitterhoeve AL \& de Haes JC. Fatigue and radiotherapy: (B) experience in patients 9 months following treatment. British Journal of Cancer 199878 907-912. (doi:10.1038/bjc.1998.600)

29 Zigmond AS \& Snaith RP. The hospital anxiety and depression scale. Acta Psychiatrica Scandinavica 198367 361-370. (doi:10. 1111/j.1600-0447.1983.tb09716.x)

30 Spinhoven P, Ormel J, Sloekers PP, Kempen GI, Speckens AE \& Van Hemert AM. A validation study of the hospital anxiety and depression scale (HADS) in different groups of Dutch subjects. Psychological Medicine 199727 363-370. (doi:10.1017/ S0033291796004382)

31 Webb SM, Prieto L, Badia X, Albareda M, Catala M, Gaztambide S, Lucas T, Paramo C, Pico A, Lucas A, Halperin I, Obiols G \& Astorga R. Acromegaly quality of life questionnaire (ACROQOL) a new health-related quality of life questionnaire for patients with acromegaly: development and psychometric properties. Clinical Endocrinology 200257 251-258. (doi:10.1046/j.1365-2265. 2002.01597.x)
32 Badia X, Webb SM, Prieto L \& Lara N. Acromegaly quality of life questionnaire (AcroQoL). Health and Quality of Life Outcomes 2004 2 13. (doi:10.1186/1477-7525-2-13)

33 Sardella C, Lombardi M, Rossi G, Cosci C, Brogioni S, Scattina I, Webb SM, Gasperi M, Martino E \& Bogazzi F. Short- and long-term changes of quality of life in patients with acromegaly: results from a prospective study. Journal of Endocrinological Investigation 2010 $3320-25$.

34 Biermasz NR, Pereira AM, Frolich M, Romijn JA, Veldhuis JD \& Roelfsema F. Octreotide represses secretory-burst mass and nonpulsatile secretion but does not restore event frequency or orderly GH secretion in acromegaly. American Journal of Physiology. Endocrinology and Metabolism 2004286 E25-E30. (doi:10.1152/ ajpendo.00230.2003)

35 Alexopoulou O, Bex M, Abs R, T'Sjoen G, Velkeniers B \& Maiter D. Divergence between growth hormone and insulin-like growth factor-I concentrations in the follow-up of acromegaly. Journal of Clinical Endocrinology and Metabolism 200893 1324-1330. (doi:10.1210/jc.2007-2104)

36 Kaltsas GA, Isidori AM, Florakis D, Trainer PJ, CamachoHubner C, Afshar F, Sabin I, Jenkins JP, Chew SL, Monson JP, Besser GM \& Grossman AB. Predictors of the outcome of surgical treatment in acromegaly and the value of the mean growth hormone day curve in assessing postoperative disease activity. Journal of Clinical Endocrinology and Metabolism $2001 \mathbf{8 6}$ 1645-1652. (doi:10.1210/jc.86.4.1645)

37 Neggers SJ, Kopchick JJ, Jorgensen JO \& van der Lely AJ. Hypothesis: extra-hepatic acromegaly: a new paradigm? European Journal of Endocrinology $2011 \mathbf{1 6 4} 11-16$. (doi:10.1530/EJE-100969)

38 Rubeck KZ, Madsen M, Andreasen CM, Fisker S, Frystyk J \& Jorgensen JO. Conventional and novel biomarkers of treatment outcome in patients with acromegaly: discordant results after somatostatin analog treatment compared with surgery. European Journal of Endocrinology 2010163 717-726. (doi:10.1530/EJE10-0640)

39 van Thiel SW, Bax JJ, Biermasz NR, Holman ER, Poldermans D, Roelfsema F, Lamb HJ, van der Wall EE, Smit JW, Romijn JA \& Pereira AM. Persistent diastolic dysfunction despite successful long-term octreotide treatment in acromegaly. European Journal of Endocrinology 2005153 231-238. (doi:10.1530/eje.1.01955)

40 van der Klaauw AA, Pereira AM, van Kralingen KW, Rabe KF \& Romijn JA. Somatostatin analog treatment is associated with an increased sleep latency in patients with long-term biochemical remission of acromegaly. Growth Hormone E IGF Research 2008 18 446-453. (doi:10.1016/j.ghir.2008.04.001)

41 Fiebrich HB, van Beek AP, Kema IP, Links TP, van den Berg G, Walenkamp AME, Sluiter WJ \& de Vries EGE. Deficiencies of fatsoluble vitamins in patients receiving long-term somatostatin analogue treatment. Alimentary Pharmacology $\mathcal{E}$ Therapeutics 2010 32 1398-1404. (doi:10.1111/j.1365-2036.2010.04479.x)

Received 1 October 2011

Revised version received 30 December 2011

Accepted 16 January 2012 